\title{
Obstáculos no processo de ensino e de aprendizagem de cálculo estequiométrico
}

\section{The obstacles in the process of teaching and learning of stoichiometic calculation}

\author{
Ana Alice Farias da Costa ${ }^{1}$ \\ Jorge Raimundo da Trindade Souza
}

\section{Resumo}

O artigo apresenta resultados de uma pesquisa realizada no município de Belém-Pará, com professores de Química e alunos do $2^{\circ}$ ano do Ensino Médio de uma escola pública e outra privada, por meio da aplicação de entrevistas semiestruturadas com o objetivo de identificar e investigar nas aulas de Química os principais obstáculos dos estudantes em relação ao aprendizado de Cálculo Estequiométrico, e assim, propor uma intervenção didática. Após análise quantitativa e qualitativa aplicou-se uma aula contextualizada utilizando um jogo didático, objetivando uma aprendizagem efetiva. Os resultados mostram que a principal dificuldade relatada tanto pelos discentes quanto pelos docentes está relacionada aos cálculos presentes no conteúdo abordado. Concluiu-se, após a intervenção didática e a aplicação de uma nova entrevista semiestruturada, que os estudantes demonstraram interesse na aula, melhor compreensão do conteúdo e assim puderam construir efetivamente o conhecimento objeto deste estudo.

Palavras-chave: Cálculo Estequiométrico; Obstáculos; Ensino de Química.

\section{Abstract}

The article presents results of a research realized in the city of Belém, Pará, with chemistry teachers and students of 2nd year of high school from a public school and one private, by the application of semistructured interviews in order to identify and investigate in Chemistry classes in the main obstacles of the students in relation to student learning Stoichiometric Calculation, and thus, propose a didactic intervention. After quantitative and qualitative analysis was applied a contextualized classroom using teaching a game, aiming at effective learning. The results show that the main difficulty reported by both students and the teachers is related to the calculations present in the content addressed. It is concluded that, after didactic intervention and implementation of a new semistructured interview, the students showed an interest in class, better understanding of the contents so they could effectively build the knowledge object of this study.

Keywords: Stoichiometric Calculation, Obstacles, Teaching of Chemistry.

\footnotetext{
${ }^{1}$ Discente do PPGQ/UFPA | analilice@hotmail.com

${ }^{2}$ ICEN/UFPA | jrts@ufpa.br
} 


\section{Introdução}

Villa (2003, p. 407) mostra que persiste nas escolas o modelo de ensino voltado para a compreensão da aprendizagem baseada na Psicologia Behaviorista, que nega a ação e atividade do sujeito que aprende, reduzindo-o a um simples catalogador de dados previamente organizados pelo professor.

Os conceitos de Química são ensinados nas escolas desde o Ensino Fundamental e mais especificamente no Ensino Médio. Porém, como muitos estudos sobre esta área mostram, a Química é apresentada ao aluno muitas vezes apenas na teoria e não na prática, e poucas vezes ela é vinculada ao cotidiano do aluno. Os professores apresentam os conteúdos por meio de aulas tradicionalistas, em que expõem os conceitos, exemplos e exercícios resolvidos e propostos que pouco estimulam o desenvolvimento dos alunos.

Entre os assuntos que os alunos apresentam dificuldade de aprendizagem encontra-se o Cálculo Estequiométrico. Seja pelos cálculos presentes neste conteúdo ou pelas reações, eles não conseguem muitas vezes realizar esses cálculos e escrever ou balancear as reações. Além de não conseguirem relacionar grandezas e compreender o enunciado da questão, para fazer os cálculos, os alunos provavelmente memorizam, de uma maneira mecânica, os passos que o professor realiza ao resolver o problema. Assim, os alunos passam mais tempo decorando do que tentando entender os conteúdos e interpretar as situações.

Quais seriam os motivos para essas dificuldades? Seria a metodologia de ensino usada pelos professores? A falta de interesse dos alunos em aprender ou dos professores em ensinar? A falta de laboratórios nas escolas e de recursos para a utilização de novas metodologias? O que professores e alunos pensam sobre isso? O que pode ser feito para mudar esta realidade? Qual seria a melhor metodologia para se ensinar Cálculo Estequiométrico de uma maneira mais significativa? Com base nesses questionamentos este estudo investigou as principais dificuldades dos alunos do Ensino Médio em aprender Química, mais especificamente Cálculo Estequiométrico.

\section{O ensino de química}

A metodologia utilizada no ensino de Química, na maioria das vezes, prioriza a memorização de conceitos, de fórmulas, de reações, ignorando a importância de mostrar aos alunos a verdadeira importância desta disciplina e o que ela representa em suas vidas. Costa et al. (2005, p. 31) mostram que a metodologia tradicional de ensino de Química na Educação Básica se destaca pela utilização de regras, fórmulas e nomenclaturas, gerando uma grande desmotivação entre os alunos. Soma-se a este fato a ausência de correlação desta disciplina com o cotidiano dos alunos, tornando a Química, que é uma ciência de natureza experimental, excessivamente abstrata.

O que leva muitos alunos a afirmarem que detestam Química? Será que é pelo fato de que a metodologia utilizada no ensino desta ciência, sem contextualização e frequentemente com ausência de experimentação, raramente oferece algum significado para o estudante? Segundo Chassot (2004, apud Santos, 2003, p. 64), o ensino que se faz, na grande maioria das escolas, é literalmente inútil. Isto é, mesmo se não existisse, muito pouco ou nada seria diferente. Souza (2010, p.36) afirma que para que o professor de 
Química não fique "invisível" e o aluno não se sinta incomodado por estar 'parado' na sala de aula, deve-se levar para o ambiente de aprendizagem som e imagem. $\mathrm{O}$ aluno dá muito valor quando participa de qualquer ação educacional, sentindo-se motivado para participar das atividades escolares.

\section{A importância de aprender química}

Não se pode mais restringir a função do Ensino Médio ao objetivo estrito de preparar para o Ensino Superior nem ao de formação profissionalizante. No contexto da sociedade moderna, não é exigido do cidadão apenas o domínio da leitura e da escrita ou o conhecimento geral das áreas de ciência e humanidades estudadas no Ensino Fundamental. Para o cidadão moderno é necessário, também, o conhecimento especifico das disciplinas científicas do nível médio (Santos, 2003, p. 47).

Cardoso e Colinvaux (2000, p.401) apud Trevisan; Martins (2006, p. 2) mostram que o estudo da Química deve-se principalmente ao fato de possibilitar ao homem o desenvolvimento de uma visão crítica do mundo que o cerca, podendo analisar, compreender e utilizar este conhecimento no cotidiano, tendo condições de perceber e interferir em situações que contribuem para a deterioração de sua qualidade de vida, como por exemplo, o impacto ambiental provocado pelos rejeitos industriais e domésticos que poluem o ar, a água e o solo. Cabe assinalar que o entendimento das razões e objetivos que justificam e motivam o ensino dessa disciplina, poderá ser alcançado abandonando-se as aulas baseadas na simples memorização de nomes e fórmulas, tornando-as vinculadas aos conhecimentos e conceitos do dia a dia do alunado.

É necessário que os cidadãos conheçam como utilizar as substâncias no seu dia-a-dia, bem como se posicionarem criticamente aos efeitos ambientais da utilização da Química e quanto às decisões referentes aos investimentos nessa área, a fim de buscar soluções para os problemas sociais que podem ser resolvidos com a ajuda do seu desenvolvimento. (Santos, 2003, p. 47). O avanço tecnológico proporcionou grandes progressos na utilização da Química para a saúde com aplicações, em várias áreas da medicina, como por exemplo, na cardiologia, na ortopedia, na endocrinologia, na neurologia etc.

\section{Obstáculos no ensino e na aprendizagem}

Muitos pesquisadores perceberam que, ao menos em relação aos conceitos científicos, o obstáculo à aprendizagem não reside apenas na falta de estrutura lógica. Em geral essas atitudes existem, mas os novos conteúdos não são aprendidos porque o aluno já possui conceitos prévios, funcionalmente equivalentes, que criam resistências cognitivas para a aquisição de determinados conceitos científicos. Deve-se, assim, eliminar o bloqueio das concepções alternativas para possibilitar a aquisição das concepções cientificamente corretas, pedagogia esta voltada para a evolução ou mudança conceitual (Giordan, 1999, p. 43-49).

É preciso estar atento às diferentes fontes de dificuldades na aprendizagem escolar. Paiva (2001, p. 3) afirma que os obstáculos didáticos são conhecimentos que se encontram relativamente estabilizados no plano intelectual e que podem dificultar a evolução da aprendizagem do saber escolar. 
Se por um lado os obstáculos epistemológicos têm raízes históricas e culturais, por outro eles estão relacionados também à dimensão social da aprendizagem. Muitos deles estão próximos de representações elaboradas pelo imaginário do sujeito cognitivo. É nesse quadro que surgem dificuldades decorrentes de conhecimentos anteriores, bloqueando a evolução da aprendizagem. (Paiva, 2001, p. 4)

Os atores centrais do processo de ensino e aprendizagem são os professores e alunos, portanto, é essencial que estes sejam considerados na ação docente, levando-se em conta suas influências no processo de aprender. Dentre os procedimentos relacionados aos alunos, destacam-se a deficiência na base teórica, o ingresso nas instituições de ensino cada vez mais cedo, ou seja, a imaturidade, e a falta de preparo para lidar com a mudança da prática pedagógica do professor que interfere de forma negativa na conduta do processo de ensino e aprendizagem, e, dessa forma, os docentes convivem com obstáculos que se apresentam sob a forma de desinteresse e indisciplina, juntamente com a deficiência na base teórica. (Rodrigues; Mendes Sobrinho, 2008, p. 438).

Segundo Rodrigues e Mendes Sobrinho (2008, p. 438), alguns obstáculos estão relacionados ao professor, tais como, lacuna na preparação específica para o exercício da docência, prática pedagógica sustentada pela dicotomia teoria e prática, trabalho didático com disciplinas das quais não tem domínio do conteúdo, linguagem e dificuldade de mudança da prática pedagógica.

Para Bachelard (1996, p.18), é impossível anular, de um só golpe, todos os conhecimentos habituais. Paiva (2001, p. 1) mostra que Bachelard observou que a evolução de um conhecimento pré-científico para um nível de reconhecimento científico passa, quase sempre, pela rejeição de conhecimentos anteriores e se defronta com certo número de obstáculos. Assim, esses obstáculos não se constituem na falta de conhecimento, mas, pelo contrário, são conhecimentos antigos, cristalizados pelo tempo, que resistem à instalação de novas concepções que ameaçam a estabilidade intelectual de quem detém esse conhecimento.

O conhecimento em Química configura-se como um valioso instrumento para a efetiva formação do cidadão, pois poderá permitir-lhe uma leitura mais crítica e consciente acerca do mundo a sua volta. O que se tem constatado é que a imensa dificuldade de se contextualizar o conhecimento discutido em sala de aula, na Química especialmente, tem múltiplos fatores. Não se respeita, nem se considera, por exemplo, o repertório de representações que o aluno tem sobre o mundo em sua volta, dos fenômenos químicos presentes no seu dia-a-dia. A disciplina Química, por sua vez, é invariavelmente ensinada como uma ciência de conteúdo estático, ficando esquecidas as questões relativas à maneira como acontece a construção desse conhecimento (Chagas 2011, p.1). Essas dificuldades relatadas representam alguns dos obstáculos observados no processo de ensino e aprendizagem de Química, o que certamente provoca entrave na construção de conhecimento nesta ciência por sua natureza experimental e presença no cotidiano dos aprendizes.

\section{Obstáculos na aprendizagem de cálculo estequiométrico}

O Cálculo Estequiométrico é uma parte da Química que estuda a quantidade de matérias envolvidas em uma reação química. Para se compreender essa parte da Química é essencial saber expressar as quantidades de uma substância em massa, número de mols, 
em volume de líquido, em volume de gás nas diversas condições de temperatura e de pressão e em volume de solução aquosa. A interpretação correta de uma equação de reação química é fundamental para o estudo dos cálculos que determinam as quantidades de substâncias envolvidas (Beltran e Ciscato, 1999, p. 83).

Assim como outros autores, Migliano (2005, apud Costa, 2008, p. 3) afirma que a falta de materiais didáticos interfere especialmente no ensino da estequiometria, uma vez que diversos autores apontam este tópico como sendo dos mais difíceis de serem compreendidos pelos estudantes.

Gomes e Macedo (2007, p. 150) relatam que é do conhecimento dos professores de Ciências o fato de a experimentação despertar um forte interesse entre alunos de diversos níveis de escolarização. Em seus depoimentos, os alunos também costumam atribuir à experimentação um caráter motivador, lúdico, essencialmente vinculado aos sentidos. Por outro lado, não é incomum ouvir de professores a afirmativa de que a experimentação aumenta a capacidade de aprendizado, pois funciona como meio de envolver o aluno em temas de pauta. No Ensino Médio, Estequiometria é um assunto pouco trabalhado em aulas práticas, o que dificulta o entendimento dos discentes.

Para Lima Neto (1999, apud Costa 2008, p. 10) o uso de modelos moleculares no ensino de Química é de grande valia para este propósito, pois sustenta a visualização das ligações químicas existentes entre os núcleos atômicos que compõem uma molécula. 0 modo como alguns temas específicos são abordados em sala de aula: ligações químicas, estruturas moleculares, balanceamento de reações, leva o estudante a imaginar a Química como uma ciência abstrata, pois muitas vezes ele não consegue conceber essas ideias no espaço tridimensional, dificultando consideravelmente o aprendizado, além de transmitir o conceito errôneo de que o estudo da Química é meramente decorativo.

Para Pio (2006, p. 7) o conhecimento sobre Cálculo Estequiométricos pode ser aplicado em muitas situações do cotidiano. A prescrição de muitos medicamentos, por exemplo, é baseada em doses calculadas a partir de determinada quantidade do agente ativo do medicamento e que são necessárias para reagir com certas substâncias no nosso organismo.

Pio (2006, p. 8) afirma, ainda, que o desenvolvimento do Cálculo Estequiométrico utiliza a linguagem matemática (aritmética e proporção), a linguagem física (unidades de medidas do SI) e a linguagem química (simbologia, grandezas e equações químicas). Segundo a literatura, a maioria dos professores considera "Cálculo Estequiométrico" um grande desafio, devido à dificuldade de aprendizagem que os alunos apresentam.

No que diz respeito às dificuldades de aprendizagem de Estequiometria no Ensino Médio, normalmente estão relacionadas com a maneira como o assunto é abordado. Muitos educadores estão somente preocupados com o aspecto matemático em que a Estequiometria está envolvida, em detrimento de uma interpretação química. Desta forma, o aluno é conduzido ao desenvolvimento do raciocínio lógico-matemático com a finalidade exclusiva de mecanizar os procedimentos para a solução de problemas envolvendo os aspectos quantitativos dos fenômenos químicos. Por outro lado, o que leva o aluno a não entender as relações matemáticas necessárias à compreensão das relações estequiométricas é a dificuldade que os mesmos apresentam em conhecimentos básicos de matemática (Hartwing, 1981 apud Migliato, 2005, p. 3).

É praticamente unânime entre professores do Ensino Médio a dificuldade que os alunos têm acerca da compreensão do significado de quantidade de matéria e mol. Muitos 
trabalhos de investigação, publicados durante os últimos anos, têm mostrado uma crescente preocupação em torno do ensino e da aprendizagem desses conceitos. Esses trabalhos apontam como causas das grandes dificuldades de compreensão desses conceitos, o pouco tempo dedicado ao desenvolvimento do pensamento no nível atômico molecular em relação ao nível representacional da constante de Avogadro - ponte essencial para a transposição entre o macroscópico e o microscópico - além da indistinção entre as grandezas, quantidade de matéria e massa (Rogado, 2004 apud Pio, 2006, p. 8).

\section{Tendências metodológicas no ensino de química}

Na área de Química, historicamente, muitos alunos demonstram dificuldades em aprender. Na maioria das vezes, não percebem o significado ou a validade do que estudam. Usualmente os conteúdos são trabalhados de forma descontextualizada, tornando-se distantes, assépticos e difíceis, não despertando o interesse e a motivação dos alunos. Além disso, alguns professores de Química também demonstram dificuldades de relacionar os conteúdos científicos com eventos da vida cotidiana. Suas práticas, em sua maioria, priorizam a reprodução do conhecimento, a cópia, a memorização, acentuando a dicotomia teoria-prática presente no ensino (Trevisan; Martins, 2006, p. 2).

A aplicação de novas metodologias de ensino é importante para aumentar o interesse dos alunos nas aulas de Química, fazê-lo mais participativo, tornando-o um sujeito ativo na construção de seu próprio conhecimento. Temos abaixo dois exemplos de metodologias de ensino alternativas, que foram utilizadas neste estudo:

\section{Uso da contextualização:}

França (2005, p. 10) ensina que se não contextualizarmos os conteúdos e simplesmente ensinarmos fórmulas e símbolos, não daremos ao aluno a chance de pensar. Não podemos esperar que nossos jovens sejam capazes de receber conhecimentos fragmentados e contextualizá-los, de forma a entender os processos que nos cercam. Os conhecimentos, quando fragmentados, só servem para usos técnicos, e não para uma releitura do mundo.

A não contextualização da Química pode ser responsável pelo alto nível de rejeição do estudo desta ciência pelos alunos, dificultando o processo de ensino e aprendizagem. Fechando um círculo, terrivelmente pernicioso para a aprendizagem dos conteúdos químicos, temos uma formação ineficiente que não prepara os professores para a contextualização dos conteúdos (Zanon e Palharini, 1995, apud Lima et al 2000, p. 26).

\section{Uso de jogos didáticos}

Santana e Rezende (2008, p. 1) afirmam que a maioria dos autores destaca os jogos como elementos motivadores e facilitadores do processo de ensino e aprendizagem de conceitos científicos, enfatizando que o objetivo dos jogos não se resume apenas à facilitação da memorização do assunto pelo aluno, mas sim a induzi-lo ao raciocínio, à reflexão, ao pensamento e, consequentemente, à (re) construção do seu conhecimento. 


\section{Metodologia}

Este trabalho foi realizado por meio de uma pesquisa qualitativa e quantitativa. Os resultados foram obtidos através da aplicação de questionários, com perguntas abertas, fechadas e mistas, direcionados para alunos da $2^{a}$ série do Ensino Médio e para professores de Química de várias instituições de ensino, a fim de evidenciar o uso de métodos alternativos de ensino como uma atividade importante para o desenvolvimento escolar do aluno.

A pesquisa foi realizada em uma escola pública e uma particular de ensino fundamental e médio na cidade de Belém, Pará,

Participaram desta pesquisa 40 professores de Química, sendo 51\% do sistema publico e 49\% do sistema particular de ensino da região metropolitana de Belém, 21 alunos da escola pública e 56 alunos da escola particular, todos da $2^{\text {a }}$ série do Ensino Médio, com uma faixa etária variando de 15 a 19 anos de idade.

A obtenção dos dados para análise se deu por meio de três questionários préformulados, constituídos por perguntas abertas, fechadas e mistas que foram respondidos pelos alunos da $2^{a}$ série do Ensino Médio e por professores de Química para avaliação da problemática em questão.

Foram aplicados questionários para os professores durante todo o primeiro semestre de 2012, para saber na visão deles qual seria a principal dificuldade dos alunos. Para os alunos, o primeiro questionário foi aplicado nas duas instituições no dia 16 de junho de 2012 e houve conversas durante esse processo com os alunos. Após o levantamento das dificuldades a aula foi elaborada e trabalhada no dia 20 de Agosto de 2012 na escola pública e no dia 23 de Agosto de 2012 na particular. Foi aplicado um segundo questionário aos alunos, logo após a aula, para avaliar suas concepções sobre o conteúdo lecionado.

A aula apresentada foi elaborada previamente através do plano de aula, cujo conteúdo de Cálculo Estequiométrico escolhido foi relacionado aos conceitos de mol e de massa, sendo utilizada como material de apoio uma apostila para reforçar o assunto ministrado e para verificar o aprendizado do aluno. As metodologias alternativas escolhidas para a elaboração desta aula, aplicadas através de uma gincana, foram a contextualização e o uso de jogos didáticos. A contextualização foi usada para mostrar aos alunos a importância deste conteúdo e como ele está presente no dia a dia e interfere na sociedade. O uso de jogos justifica-se pelo fato de tornar a aula mais dinâmica e o aluno mais participativo.

Foi realizada uma análise dos dados obtidos dos questionários dos professores de Química e dos alunos e, cujos resultados foram mostrados neste trabalho através de gráficos e respostas subjetivas, com o intuito de evidenciar a necessidade do uso de métodos alternativos no ensino de Química.

\section{Resultados e discussão}

Cerca de $80 \%$ dos professores entrevistados são licenciados em Química. A faixa etária predominante é entre 25 e 35 anos (40\%) e a maioria (80\%) leciona há mais de dez anos. Do total de professores que participaram da pesquisa $59 \%$ utilizam novas metodologias de ensino (jogos, contextualização etc.). Aproximadamente $87 \%$ dos entrevistados disseram fazer uso de algum tipo de experimentação em suas aulas. 
Para 43\% dos professores pesquisados, as maiores dificuldades no estudo de Cálculo Estequiométrico são os próprios cálculos matemáticos. Os educadores relataram que essa dificuldade é devido à falta de fundamentos da Matemática e de interesse por parte dos alunos. Para minimizar este problema, os professores usam questões do cotidiano e ministram aulas de Fundamentos da Matemática para dirimir os problemas de Cálculo Estequiométrico.

Quando questionados sobre qual a razão para as dificuldades apresentadas pelos alunos, os professores, tanto das escolas particulares quanto da rede pública afirmaram:

"Devido à diversificação de associações que podem ser utilizadas nos cálculos, além das dificuldades de interpretação dos dados".

"Porque os alunos têm dificuldades de matematizar".

"Falta de base em Matemática nas series iniciais, pois nesse momento a maioria tem desinteresse pela disciplina".

"Dispersão e falta de interesse (porque tal assunto é muito monótono e requer habilidade do professor)".

Aproximadamente $67 \%$ dos alunos entrevistados têm idade superior a 17 anos. Do total, 60\% gostam de Química, porém afirmam que é uma disciplina difícil, cheia de fórmulas e cálculos. Mesmo com essa definição, 70\% deles disseram compreender o que Ihes é ensinado, porém 52\% não conseguem aplicar no seu dia a dia o que aprenderam na escola.

Com relação ao Cálculo Estequiométrico, 61\% dos alunos entrevistados responderam que não gostam desse conteúdo, sendo que 68\% deles apresentam dificuldade para compreender o que é ministrado sobre o assunto, principalmente os cálculos matemáticos.

Alguns relatos representativos resumem a opinião dos alunos sobre as dificuldades encontradas nas aulas que abordam Cálculo Estequiométrico:

"Deve ter mais dinâmica e prática. É muito chato ver só cálculos, gostaria de aprender na prática".

"O professor deve tentar deixar a aula mais dinâmica, apesar de gostar muito de Química, tem aulas que ficam muito monótonas".

"Apresentar o assunto e não complicar o assunto mais do que ele já é".

"Deve apresentar mais exemplos".

"Seria bem melhor se fosse aulas práticas (aulas em laboratório)".

Após a intervenção didática, 85\% dos alunos que participaram disseram compreender o conteúdo que foi ministrado. Sendo que $75 \%$ conseguiram relacionar o conteúdo ao seu cotidiano. Um número considerável de aprendizes relatou que após a intervenção didática conseguiram superar suas dificuldades. Na opinião destes alunos, aulas mais dinâmicas, com experimentos e resolução de mais exercícios que apresentem algum significado para os mesmos, podem ajudar na compreensão dos fenômenos estudados.

A pesquisa desta experiência didática revelou, também, realidades distintas quando foi estabelecida a evolução dos alunos nos dois sistemas de ensino (público e privado). Com a aplicação da aula contextualizada foi possível observar que houve melhora na compreensão dos alunos, tanto da rede pública como da rede privada: $83 \%$ e $87 \%$, respectivamente. Porém, aproximadamente de $66 \%$ dos alunos da escola pública relataram ainda sentir 
dificuldades, já na escola privada este dado foi de 47\%. Por outro lado, 100\% dos alunos da escola pública conseguiriam relacionar o conteúdo, da maneira como foi trabalhado, com o seu dia a dia; já na escola privada, 50\% puderam identificá-lo no seu cotidiano. Isso aponta que a utilização da contextualização e dos jogos didáticos são metodologias essenciais nos processos de ensino e aprendizagem de Química, independente do sistema de ensino em que o professor desenvolve suas atividades como educador.

\section{Considerações finais}

O ensino da Química apresenta obstáculos didáticos e epistemológicos que influenciam no processo de ensino e aprendizagem. Uma das dificuldades presente nessa disciplina, apontada por professores e alunos, é a abstração. No conteúdo de Cálculo Estequiométrico, objeto deste estudo, é onde este fato se torna mais presente. Conceitos como moléculas, mol, massa de um átomo, volume etc. não são palpáveis. E as dificuldades em se obter materiais didáticos de apoio tornam o processo mais difícil.

É preciso ressaltar a presença da Química em todos os parâmetros da informação para evitar a fragmentação do conhecimento, pois o conteúdo de Cálculo Estequiométrico não precisa apenas executar cálculos (Matemática), mas da interpretação dos questionamentos (saberes de outras ciências e saberes atitudinais).

Quando existe uma dificuldade ou um obstáculo, eles precisam ser superados. Aulas tradicionais, "quadro e giz", ou hoje o pincel para quadro branco, não são suficientes para melhorar o ensino e suprir as necessidades dos alunos ao longo do tempo. É preciso aplicar novas metodologias, para buscar a melhoria do ensino e da aprendizagem. Os professores pesquisados neste estudo, notando essa necessidade, estão construindo suas aulas a partir de contextualização, seja com experimentos em laboratório, seja com o uso de softwares, entre outros. Mesmo os professores que disseram ter uma aula tradicional utilizam, em sua maioria, a contextualização. Geralmente não é isto que se observa nas aulas de Química, e às vezes acontece com uma concepção equivocada de contextualização.

A principal dificuldade que os alunos apresentam em relação ao conteúdo de Cálculo Estequiométrico, de acordo com os professores entrevistados, é o conteúdo relacionado aos cálculos, proporcionado por uma base construída de modo incorreto em Matemática, pré-requisito essencial para desenvolver este conteúdo.

A falta de base dos fundamentos matemáticos dificulta a execução de problemas envolvendo a Estequiometria. Sem saber fazer relações de proporção, regras de três, os alunos passam a sentir dificuldades em Química; mas, segundo os professores de Química entrevistados, essa dificuldade está na maioria das vezes no ensino de Matemática. Neste caso, se o professor de Química ignorar que o aluno apresenta um obstáculo epistemológico, o mesmo vai se inserir em um problema clássico de obstáculo didático, o que torna inócuo o seu trabalho como educador.

As metodologias alternativas de ensino (experimentação, jogos didáticos, contextualização, uso de projetos, softwares etc.) são estratégias para apresentar aos alunos aulas mais dinâmicas, interessantes, tornando-os participantes ativos na construção do conhecimento, interessando-se mais pelas aulas, questionando e compreendendo porque é importante estudar Química.

Ao final da pesquisa e análise dos resultados, pode-se perceber a importância e eficiência de se usar metodologias alternativas no processo educacional, pois a aula 
tradicional mostra um conteúdo "sem sentido" para os estudantes, e a partir do momento que se começa a contextualizar o ensino de Química, apresenta-se ao educando a importância desses conteúdos, e os mesmos podem relacionar o que aprendem em sala de aula com o seu cotidiano, tendo assim uma aprendizagem mais significativa.

Cálculo Estequiométrico é descrito por estudantes como um conteúdo de alto grau de complexidade. É preciso que os professores de Química tenham consciência de que a metodologia utilizada ainda é insuficiente para produzir nos alunos um aprendizado esperado. Todavia, é necessário haver empenho por parte do corpo docente desta disciplina para minimizar as dificuldades. Portanto, poderiam utilizar mais frequentemente metodologias alternativas de ensino, para aprimorar e dar mais significado ao ensino de Química, uma vez que estas tendências metodológicas são bem aceitas pelos alunos.

Após a pesquisa feita com os docentes e alunos e a aplicação de uma aula contextualizada, observou-se, pelos resultados, um melhor aprendizado dos estudantes. Portanto, é possível afirmar que afastar-se de aulas tradicionais e aplicar metodologias alternativas de ensino conduz a resultados positivos. Associar a prática e a teoria, seja em laboratório ou no cotidiano do aluno, é formidável. Enfatizando o caráter de utilidade e experimental de Química como uma ciência que desperta interesse e curiosidade. No entanto, a utilização de uma metodologia inadequada produz um aprendizado ineficaz nesta disciplina.

Obviamente, para que essa mudança ocorra, os profissionais envolvidos neste processo precisam ser capacitados. Um farmacêutico ou um bacharel não tem compromissos e nem formação voltada para lidar com mudanças necessárias para o sistema educacional. O profissional professor não pode ser substituído por um profissional de outra área como se ensinar fosse algo banal e simples.

A educação, principalmente de Ciências, que é algo tão dinâmico, precisa ser acompanhada pelos professores que devem inseri-la na cultura do aluno, pois o docente, mesmo tendo conhecimento prévio, está aberto a interagir com o novo, desde que faça algum sentido e seja útil para a sua vida cotidiana.

Não se pode dizer que a utilização de novas formas de ensino resolverá todos os problemas de aprendizagem, mas é um passo importante para a sua melhoria. Através da metodologia aplicada, no caso a contextualização, houve um avanço no processo de aprendizagem, no entanto parte dos alunos ainda sentiu dificuldade na construção do conteúdo.

\section{Referências}

Bachelard, G. (1996). A formação do espírito cientifico: contribuição para uma psicanálise do conhecimento. São Paulo: Contraponto.

Beltran, N. O. \& Ciscato, C. A. M. (1999). Química. São Paulo: Cortez.

Chagas, J. A. S. das. (2011) Obstáculos encontrados no processo de compreensão do conceito de reação química. Artigos da Feira Científica e Cultural da UFPE/CAp, Recife.

Costa, T. S. et. al. (2005). A corrosão na abordagem da cinética química. Química Nova na Escola, São Paulo, v. 22, p. 31-34.

Costa, E. T. H.(2008). Uma proposta diferenciada de ensino para o estudo da estequiometria. Produção didático-pedagógica da UEM, Maringá (PR). 
França, A. A. (2005). A Contextualização no Ensino de Química: visão dos professores da cidade de Sete Lagoas/MG. Monografia (Curso de Especialização no ensino de Ciências) - Faculdade de Educação. Universidade Federal de Minas Gerais.

Giordan, M. (1999). O Papel da Experimentação no Ensino de Ciências. Química Nova na Escola, São Paulo, v. 5, n.10, p. 43-49.

Gomes, R. S. \& Macedo, S. da H. (2007). Cálculo estequiométrico: o terror nas aulas de Química. Vértices, v. 9, n. 1, p. 149-160.

Lima, J. de F. L. de et al. (2000) A contextualização no ensino de cinética química. Química Nova na Escola. n. 11, Maio.

Migliato, J.R.F. (2005). Utilização de Modelos Moleculares no Ensino de Estequiometria para alunos do Ensino Médio - Estequiometria. 2005. Dissertação de Mestrado - UFSCar, São Carlos (SP).

Paiva, L. C. (2001). Obstáculos epistemológicos e didáticos. Acesso em 01 de nov., 2011, http://people.ufpr.br/ trovon/cursos/especializacao2009/obstaculos.pdf.

Pio, J. M. (2006). Visão de alunos do ensino médio sobre dificuldades na aprendizagem de Cálculo Estequiométrico. Monografia (Graduação de Licenciatura em Química) - Faculdade de Educação, Universidade Federal de Minas Gerais, Belo Horizonte.

Rodrigues, M. T. P. \& Mendes Sobrinho, J. A. C. (2008). Obstáculos didáticos no cotidiano da prática pedagógica do enfermeiro professor. Revista Brasileira de Enfermagem, Brasília, 61 (4), p. 435-440.

Santana, E. M. de. \& Rezende, D. de B. (2008). O uso de jogos no ensino e aprendizagem de Química: uma visão dos alunos do $9^{\circ}$ ano do Ensino Fundamental. XIV ENEQ. UFPR, Curitiba.

Santos, W. L. P. dos, \& Schnetzler, R. P. (2003). Educação em Química: compromisso com a cidadania. Ijui (RS): Unijuí.

Souza, J. R. T. (2010) Prática Pedagógica em Química: oficinas pedagógicas para o ensino de Química. UFPA: Belém.

Trevisan, T. S. \& Martins, P. L. O. (2006). A prática pedagógica do professor de Química: possibilidades e limites. UNIrevista. v. 1, n. 2, abril.

Villa, S. M. de S. (2003). As implicações dos obstáculos epistemológicos no ensino de Ciências. Revista da FAEEBA - Educação e Contemporaneidade, Salvador, v. 12, n. 20, p. 405-412, jul/dez. 